\title{
Ambulatory Treatment of Plantar Leprosy Ulcers
}

TIO (TIONG HOO), * HAN (sik hIAN) $\dagger$ and KUTUT SANTOSO.†

A chronic feature of invalidism in trophic disturbance in leprosy is the plantar ulcer (s). W.H.O. reports 1,2 disapprove any walking without special protection and stress that it is wrong ${ }^{1}$ to ask a patient to come to a clinic for dressing. They advocate complete rest of the foot for about a month otherwise use plaster casts. Absolute bedrest, as the W.H.O. reports correctly state, is very difficult in rural areas and plaster casts are preferable because these still allow limited walking.

Obviously complete rest is not very practical because most leprosy patients belong to the poor class and cannot afford to rest for a month. Plaster casts are not only inconvenient for the patient but a burden to medical personnel as well. And in rural areas it might even be impossible because they easily get wet or break during work in the field.

The authors, therefore, tried to find another simple method for treating these ulcers which will cause not too much inconvenience to the patients, are easy to apply in rural areas and require little effort from medical personnel.

Since it is known that walking causes ulcers or prevents their healing we have focused our attention on the way of walking and localisation of the ulcer(s). Natural walking is done by passing the legs (and ankles) closely to each other with the feet in parallel position. If this is done the foot unwinds on the ground as shown in figure I, with push-off mostly at A-B.

\section{NORMAL WAY OF WALKING}

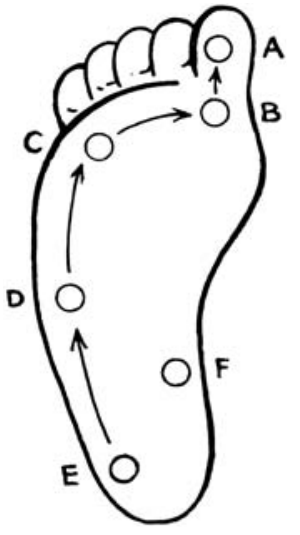

$$
\begin{aligned}
& \text { P.O. = PUSH-OFF POINTS. (A-F) } \\
& \text { PARALLEL FEET:P.O.A-B (C) } \\
& \text { 1/ EXOROTATED FEET: P.O.B-C (A) } \\
& \text { i PES VARUS :P.O. D (C-E) } \\
& \text { i PES VALGUS :P.O. B-F }
\end{aligned}
$$

\section{FIGURE I}

*National Institute of Health, Surabaya.

$\dagger$ Provincial Directorate of Health, East-Java.

Ambulatory Treatment of Plantar Leprosy Ulcers 
During push-off two important factors are obvious :

I. The whole body weight is concentrated on an area of less than one square inch.

2. Rubbing takes place at the push-off point. The provocative action of factor $I$ is clear. Fig. 2 shows that rubbing (of the sandal belt) may cause ulcer(s).

The authors concluded therefore that pressurized rubbing is the causative external factor and consequently studied the push-off site and the localisation of the ulcer(s).

It was found that all ulcers occur on the pushoff point(s). Except in cases of pes valgus, all push-offs take place along the line A-D. When the feet are held parallel the push-off points usually are in A or B, but in few cases the pushoffs may be more lateral $(B-C)$ in one or both $\operatorname{leg}(\mathrm{s})$. push-offs need not necessarily be found on similar sites on both plantae especially when one foot is held straight (parallel) and the other in a more exorotated position. Walking in exorotation moves the push-off laterally $(\mathrm{B}-\mathrm{C})$, or even to $\mathrm{D}$ in extreme exorotation and in pes varus. This will explain the finding of Srinivasan's $^{3}$ series where most of the ulcers were found in $\mathrm{A}$ and $\mathrm{B}$ and on the line $\mathrm{B}-\mathrm{C}$ in front of the metatarsal heads, under the proximal phalanges. Ross ${ }^{4}$ also found that these ulcers were actually lying in front of the metatarsal heads and not directly under them. These are obviously the push-off points.

More lateral push-offs, especially in flat feet, may not be restricted to one point and can cover several points.

It is furthermore not surprising that multiple ulcers and hyperkeratosis preceding or resulting from ulcers, can be found on the unwinding edge $\mathrm{E}-\mathrm{A}$ along which the whole body weight moves with some rubbing (Fig. 3).

Initial trials for treatment of plantar ulcers were carried out at the National Institute of Health; $3 \% \mathrm{H}_{2} \mathrm{O}_{2}$ was used for cleaning crypts in the ulcer followed by plugging with zincoil ( $75 \%$ zinc oxide $+25 \%$ cod liver oil) for drying weeping ulcers. The zincoil plug forces the patient to walk with the foot in a different position resulting in a different push-off point and as such relieving the ulcer from previous pressurized rubbing. Thus, while the patient walks about freely, the ulcer also gets appropriate rest.
That the push-off points are moved to a different site, is clearly demonstrated by cases S 693/63 (National Institute of Health) see pictures $4-7$.

From the above it was concluded that the guiding principles for simple treatment could be: 'give the ulcer $(s)$ rest while allowing the patient to walk freely but in a different (therapeutic) way'. This could cause another ulcer for which another solution, could be found (see discussion).

In trials in the National Institute of Health with outpatients, ulcers which were of years duration were healed in several weeks only, but correct evaluation of the therapy was rendered difficult by irregularity in the attendance of the patients.

Controlled trials in a closed leprosy community were desirable for which a leprosy colony, Sumber Glagah, was selected. For convenience's sake the authors devised the symbols as shown in figure 8 , for use on the patient's cards. Normal (causative) way of walking was studied and a different (therapeutic) way taught. If ulcers occured at $\mathrm{A}-\mathrm{B}$, mostly because of walking with parallel feet the patients were instructed to walk with exorotated feet, which as initial trials suggested, would be sufficient in most cases. The opposite treatment for lateral ulcers is obvious. If $\mathrm{A}-\mathrm{B}-\mathrm{C}$ ulcers could not be healed quickly enough, then walking in the knees by lifting the thighs was taught which moves the push-off closer to the heel. In this connection it is noteworthy that the traditional tight sarong of Indonesian women makes this way of moving about difficult. For medial ulcers a way of walking without pes varus manner via knees and ankles was also devised. Consequently for lateral ulcers walking with $\mathrm{X}$-knees/ankles was taught.

From a theoretical point of view the following complicating factors were anticipated:

\section{Drop foot}

In such cases the logical site for ulcers is the distal side of the foot. Exo- or endorotation of the foot are impossible. The only way of changing the push-offs is lifting the thigh preferably supported by a walking stick. A low-heeled clog with higher distal end and supporting bridge in the rear could be helpful. 


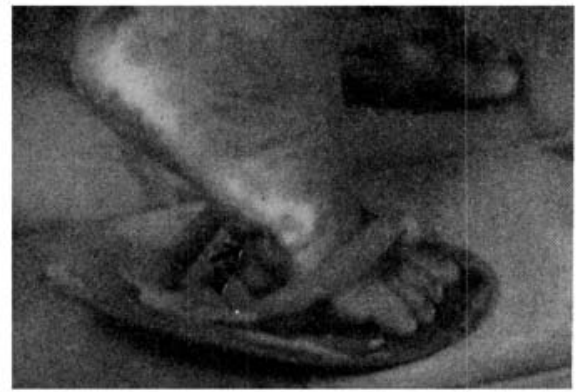

FIG, 2

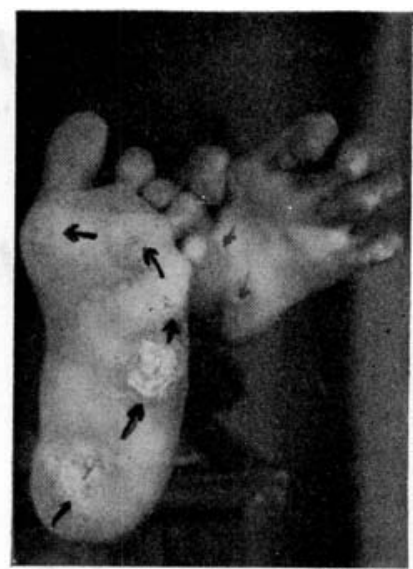

FIG. 3

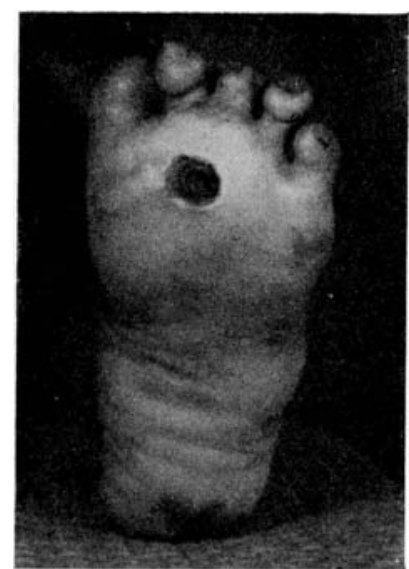

FIG. 4

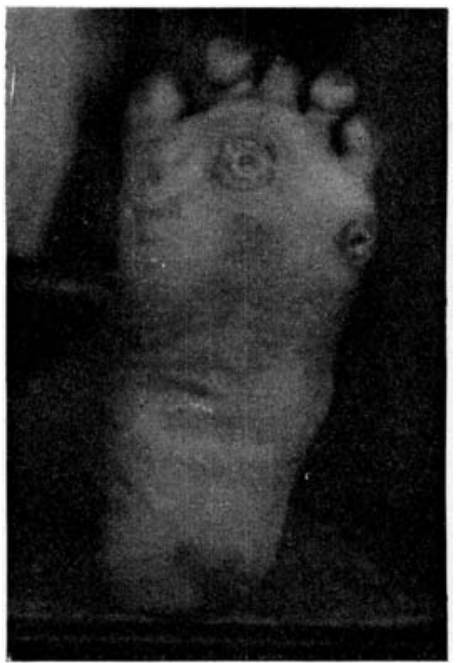

Fig. 5

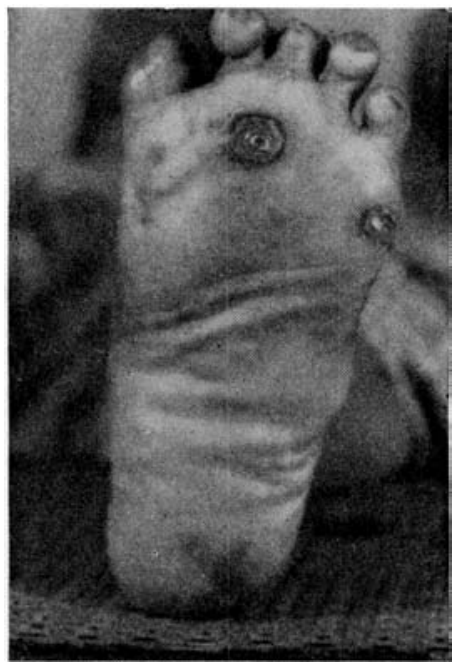

FIG. 6

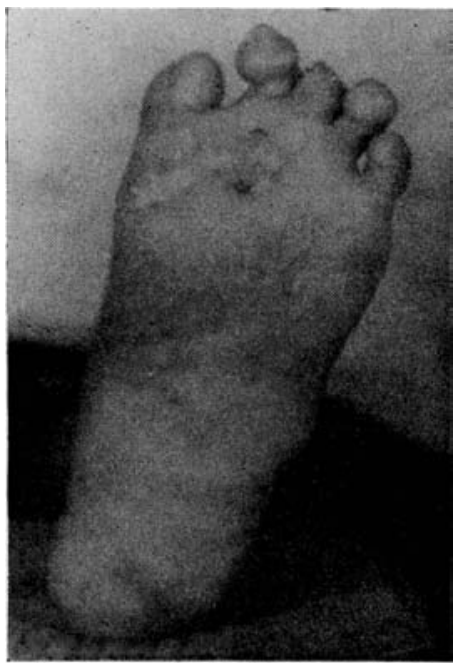

FIG. 7

\section{Rigid foot and stiff ankle}

This of course would impair free movement of the feet. A walking stick would seem to be of some help.

\section{Flat foot and elephantiasis}

Flat feet predispose to elephantiasis and can lead to multiple ulcers because the push-off point is widened to cover a large area. Manoeuvring of the foot is restricted and finding new push-off points difficult. A walking stick might relieve the pressure. Lif ting the thigh is indicated in distal ulcers.

\section{Intelligence}

Low I.Q. might interfere in teaching new ways of walking.

In Sumber Glagah, 44 patients with plantar ulcers were submitted to the above mentioned treatment. After cleaning with peroxide, three different ointments, viz.

$-75 \%$ zinc oxide $+25 \%$ cod liver oil. idem $+2 \%$ chloromycetin

- ung. zinci morrhuatis B.C.P. I $934^{*}$.

were tried out on approximately equal numbers of patients.

* Weight Layman \& Umney Ltd., Southwark, London, S.E. I. courtesy of U.N.I.C.E.F. 
NORMAL WAY OF WALKING

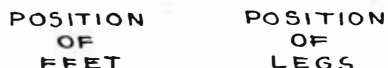

LEGS
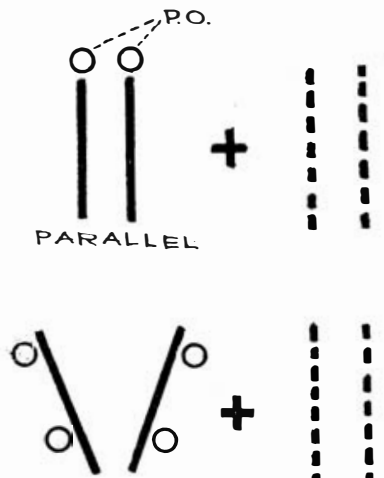

EXOROTATION

$$
: \vdots
$$
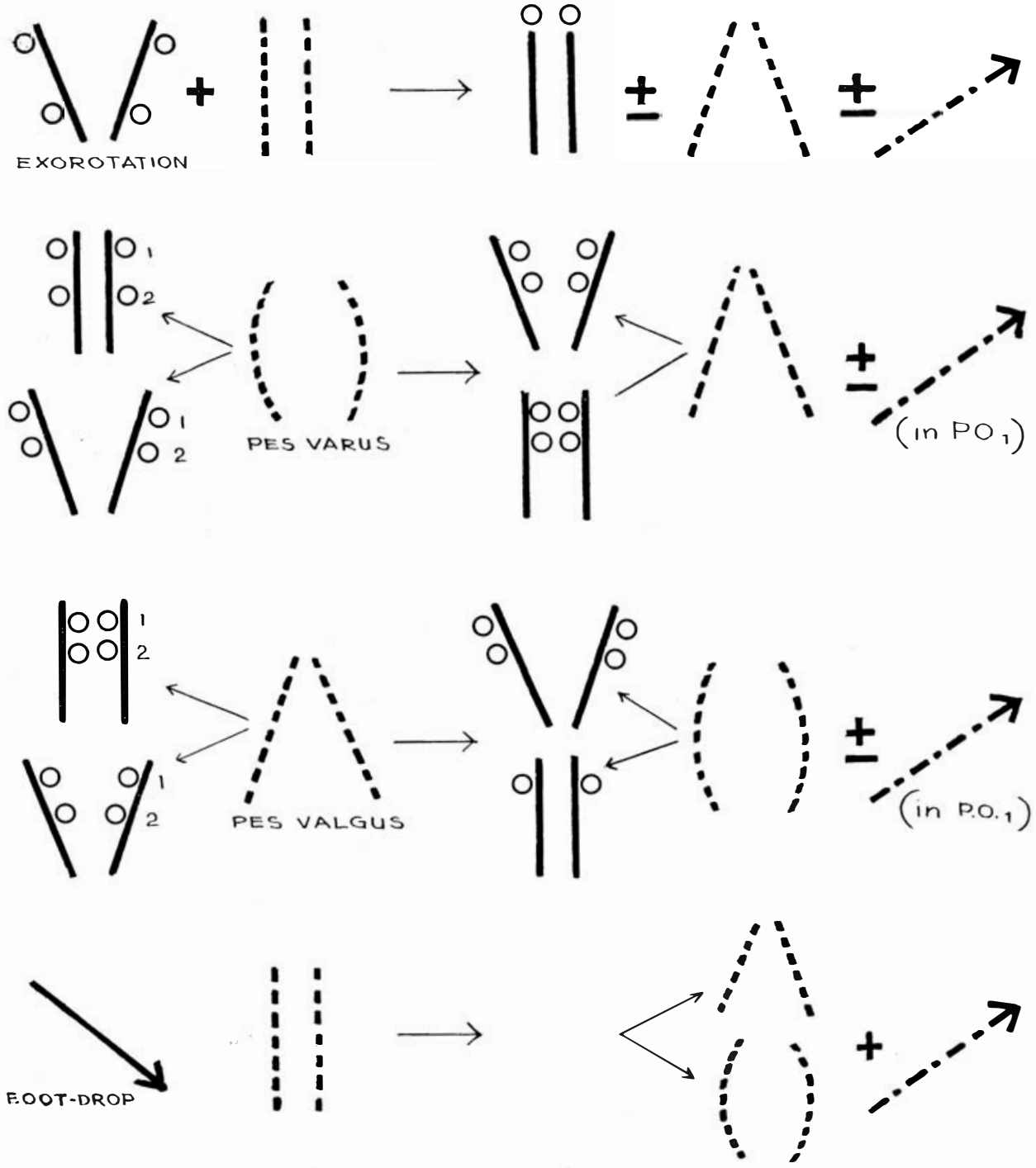

FIGURE 8

THERAPEUTIC way OF WALKIng

$\begin{array}{ccc}\text { POSITION } & \text { POSITION } & \text { LIFTING } \\ \text { OF } & \text { OF } & \text { OF } \\ \text { FEET } & \text { LEGS } & \text { THIGH }\end{array}$

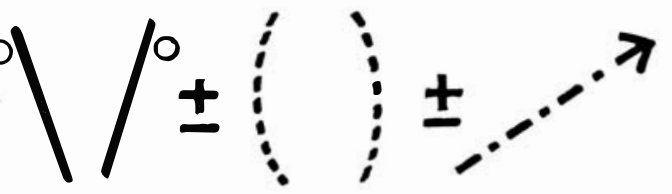

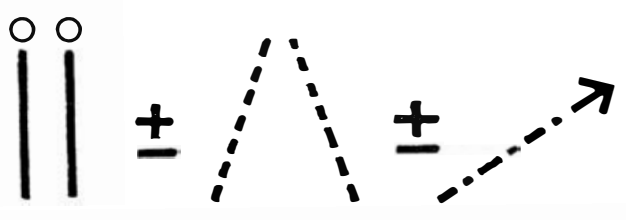

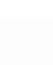


The results were as follows:

only ro out of the 44 leprosy patients with plantar ulcers had none of the afore mentioned anatomical anomalies.

There were (mostly in combination):

$\begin{array}{ll}\text { Io drop-feet } & : 4 \text { bilateral } \\ \text { Io rigid feet } & : 7 \text { bilateral } \\ \text { 2 I flat feet } & : \text { bilateral, unequal } \\ \text { I o elephantiasis } & : \text { bilateral, unequal } \\ 3 \text { pes varus } & : \text { unilateral } \\ 3 \text { pes valgus } & : \text { unilateral }\end{array}$

This seems to indicate that, next to trophic disturbances, anatomical anomalies are another important intrinsic cause of plantar ulcers.

After 2 months (9 weeks) an evaluation was made of the results obtained:

- All ulcers showed clear and sometimes even dramatic improvement/healing

- Of 27 patients with ulcers on both plantae:

I 3 healed on both plantae.

I I healed on one foot; of the other I I unhealed feet, 8 were on the right planta and 3 on the left.

in 3 patients ulcers on both plantae were not healed (yet).

- Ulcers on all io anatomical normal feet healed within 9 weeks.

- $7 \mathrm{I}$ ulcers (40 on the right, $3 \mathrm{I}$ on the left planta) of I month - I 5 years duration were healed in those 9 weeks (as extremes: in 2 patients, I 5 year old continuously existing multiple ulcers of various sizes and depths were healed in $\mathrm{I}-4$ weeks but in one patient ulcers of only 2 months duration required as much as 9 weeks).

- These 7 I ulcers involved 6 drop feet, I 8 rigid feet, i 9 flat feet, 6 flat feet, 6 elephantiasis, 2 stiff ankles, I pes varus in various combinations. Three patients had a low I.Q.

Forty ulcers were on the right, $3 \mathrm{I}$ on the left plantae.

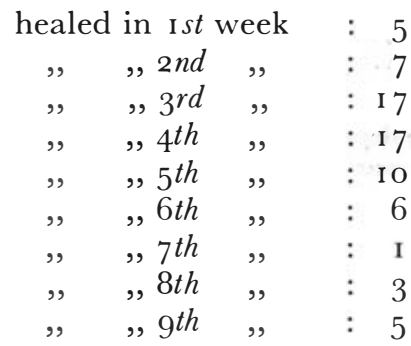

- 22 ulcers, 9 on the left and I 3 on the right planta were not healed after 9 weeks. All feet involved had anatomical deviations mostly in combination. There were 5 drop feet, 6 rigid feet, I 4 flat feet, 7 elephantiasis, 6 stiff ankles, 2 pedes vari and 2 pedes val gi.

- Out of 4 patients with low I.Q. 3 recovered within 2 months; the only non-healed one suffered from a combination of rigid, flat feet and elephantiasis.

\section{IS G USS I O N}

Although not all patients could be healed within 2 months this simple method can be regarded as satisfactory especially since all patients were allowed to walk as they pleased and $75 \%$ of the ulcers were healed and the rest showed clear improvement. In the not completely healed ulcers no X-ray pictures could be made for detecting sequestra and in one case even an amputation was originally thought necessary due to severe fixed pes varus. In other cases anatomical anomalies seemed to hamper the healing process.

This treatment can easily be applied in rural areas and no restrictions on walking need be imposed as long as the patients are willing and able to walk in the taught (therapeutic) way. When two out-patients did not turn up after running out of their supply of peroxide and zincoil, their improved ulcers (of 4 years and 5 months duration) were completely healed when they turned up again after several weeks, during which they claimed to have been walking in the taught way only without local treatment. This all the more stresses the therapeutic effect of this method.

For psychological reasons trials without ointment were not made in Sumber Glagah. No difference was found in the effect of the three ointments. The $75 \%$ zinc oxide $+25 \%$ cod liver oil ointment, however, was preferred because it glued and stuck easier and better to the ulcer while unguentum zinci tended to fall out and needed supporting dressing. When for some days no zincoil was available ulcers started to 'weep' again.

Of the improved but not yet completely healed ulcers a greater number was found on the right planta. It seems possible that this is due 
to the fact that most people are skilful and therefore have a more powerful kick-off on the right side.

In the duration of the ulcer neither its size nor depth need necessarily delay complete healing, although there was no doubt some correlation. The mysterious severity of the socalled 'trophic' disturbance seems to play an important role (see limits of healed ulcers).

Anatomical anomalies, although a hampering factor, need not necessarily prevent healing of the ulcer(s).

Low I.Q. would not appear to be an important factor because the sticky ointment seems to force the patient to walk with his/her foot in a different position.

When new ulcers on new P.O. points arose owing to the different way of walking, they can be treated by either changing the way of walking from day to day or, in case of distal ulcers, by walking in the knees by lifting the thighs. In more proximal ulcers walking on tip-toe might help or walking either in pes varus or pes valgus manner in the knees/ankles. All sorts of combinations can be taught to avoid a fixed push-off point.

\section{GOMMENTS}

This treatment seems to be most practical especially in rural areas where zincoil can be handed to the patients wrapped in plastic. It would, however, appear that this method could be even more simplified for large rural areas if patients were only taught to walk differently (therapeutically) and to clean their ulcers with antiseptic decocts of local herbs. These trials will be carried out by one of us $(\mathrm{H})$ in another leprosarium. Whether weeping of the ulcer is a disturbing factor for healing will then be estimated.

In non-plantar ulcers it was observed that pressurized rubbing existed from the inside viz. at malleoli, Achilles tendon or bone protuberances on a non-elastic thickened, hardened skin with no or little subcutaneous fat.

Here too a different way of walking relieves the pressurized rubbing i.e. for ulcers on the lateral malleolus and other parts of the foot, walking in pes valgus position in the ankle is a solution. For medial ulcers walking in pes varus style is advisable. For ulcers above the Achilles tendon walking on tip-toe assisted by a walking stick relieves the internal pressurized rubbing.

When sandals are used for feet with stiff, hardened skin, it would appear to be sensible to use foam rubber under the sandal-belts and ample talcum to minimize pressurized rubbing.

With regard to the primary cause c.q. the trophic disturbance it would appear that intraneural injections of corticosteroids seem to be helpful as mentioned in an earlier paper ${ }^{5}$. Since then other similar encouraging results were obtained ${ }^{6}$ and large scale trials in cases with various symptoms of trophic disturbances such as multiple ulcers, drop foot, elephantiasis, thickened toes, are now being carried out for further evaluation of this treatment. Unfortunately no intra-neural injectable sulphones are at our disposal which would be a real causal treatment for any trophic disturbances.

It is obvious that any treatment for trophic disturbances should start as early as possible to prevent formation of sequestera or other irreparable damage.

\section{S UMMAR Y}

A simple and cheap ambulatory treatment for leprosy ulcers, especially suitable for rural areas, is described and treatment of trophic disturbances is discussed.

\section{LITER A TURE}

I. W.H.o., 5 September I96o ('Principles of Rehabilitation in Leprosy').

2. w.H.o., 27 September I96o (Report on the Scientific Meeting on Rehabilitation in Leprosy, Vellore (India), 2 I-29 November 1960).

3. SRINIVASAN, H.: Lep. India, I963-35-1 i 9 .

4. Ross, w. F.: Lep. Rev., I 962-33-25.

5. тіо (Tiong Hoo); Lep. Rev. r 966-37-93.

6. тіо (Tiong Hoo): Aesthetic management in leprosy (to be published).

P.s. Owing to the departure of one of us $(\mathrm{T})$ this investigation had to be restricted to two months only. 